\title{
Обзорная информация
}

УДК 338.12.017:629.113

\author{
Российский рынок легковых \\ автомобилей как часть глобального рынка. \\ Состояние и перспективы развития
}

\author{
(C) 2014 г. И.Я. Гальперин*
}

За последние 20 лет рынок автомобильной продукции России существенно изменился. В начале 1990-х гг. на нашем рынке в целом доминировали отечественные производители. Несмотря на существенные претензии потребителей к качеству автомобилей, отрасль выглядела выигрышно благодаря относительно низким ценам на свою продукцию и развитой сети автодилеров и автомастерских, где можно было в любой момент отремонтировать машину или купить запчасти. Иностранные производители могли предоставить российскому потребителю хорошее качество, но по более высокой цене.

Однако в 90-е гг. XX в. облик российского авторынка начал меняться. Отягощенные проблемами переходной экономики 1990-х годов, российские производители не могли и не хотели вкладывать средства в модернизацию производства и резкое повышение качества на долгосрочную перспективу. К тому же у них не было для этого должных стимулов. Таможенная защита внутреннего рынка автомобилей в России создавала для отечественных производителей искусственную ценовую защиту.

С одной стороны, таможенная защита предотвратила банкротство отечественных автопроизводителей и смежных отраслей промышленности, сохранила миллионы рабочих мест и стабильных налогоплательщиков. Но, с другой стороны это способствовало консервации многих негативных и нерыночных факторов работы автомобильных компаний, у которых вновь не оказалось стимула для полномасштабного обновления и перехода на новые принципы работы.

Состоявшееся в 2012 г. вступление России во Всемирную торговую организацию означает, что российские производители будут вынуждены существовать на внутреннем рынке на равных со своими крупнейшими мировыми конкурентами.

Ключевые слова: автомобильный рынок, автопром, автомобилестроение, автомобилизация, автомобильная отрасль, развитие автомобилестроения, отечественный автопром.

Современное автомобилестроение в мире давно приобрело глобальный характер. Процессы глобализации и мирового разделения труда обусловили превращение автомобилестроения в важную и неотьемлемую часть мировой экономики. В первом десятилетии XXI в. ситуация на мировом рынке легковых автомобилей сложилась такая, что совокупное предложение формируется в тех странах мира и на континентах, где для этого есть соответствующие технологические возможности и выгодные условия для размещения производства с точки зрения издержек, транспортной доступности, обеспеченности сырьем и т.д.

При этом американские и европейские производители не наращивают производство, а скорее сни-

* Соискатель степени канд. экон. наук, каф. управления ВЭД Московского Государственного Института Международных Отношений (Университета) МИД РФ, 119454 , Россия, Москва, просп. Вернадского, д. 76, galperin_igor@mail.ru. жают его в своих традиционных местах размещения производственных мощностей. В странах АзиатскоТихоокеанского региона господствует совершенно иная тенденция. Здесь происходит гораздо более динамичный рост производства и потребления легковых автомобилей. Уровень благосостояния в этих странах пока сравнительно ниже, чем в развитых, поэтому именно здесь преобладает спрос на недорогие автомобили. Производство в развитых странах с высокими издержками на труд и сырье становится все более невыгодным даже для крупнейших компаний. Поэтому именно в развивающихся странах автопроизводители стараются разместить свое производство. Одновременно крупнейшие компании стараются размещать производство с такой целью, чтобы на новом месте квалификация рабочих была на высоком уровне, а зарплаты были значительно ниже, чем в странах традиционного производства. Например, завод по производству автомобилей Volkswagen Touareg, Porsche Cayenne и Audi Q7 разместили в Словакии. В быстроразвивающихся странах других регионов мира - в ЮАР, 
Китае, Бразилии, Индонезии в Пакистане - производят в основном автомобили, ориентированные на внутренний рынок. На экспорт отправляются только те машины, производство которых превысило внутренние потребности [1].

Таким образом, рост объема мирового производства именно в развивающихся странах является одной из наиболее значимых тенденций мирового развития автомобильного рынка. Одновременно и в связи с этим обостряется также конкуренция за размещение своего производства в других странах, за ресурсы, используемые в автомобильном производстве.

Прежде всего, следует обратить внимание на то, что его глобальный характер предполагает дислокацию производителей и потребителей по всему миру и высокий уровень интернационализации в производстве и потреблении конечной продукции. При этом не исключается некоторая специфика в тенденциях формирования регионального совокупного предложения и спроса, отражающаяся в динамике объемов и структуре продаж в рамках регионов и в мире в целом (табл. 1).

Как следует из данных, представленных в табл. 1, мировому рынку автомобилей присуща высокая динамика развития. За 2005-2013 гг. объемы продаж легковых автомобилей в физическом выражении выросли почти на $39 \%$.

Общие тенденции развития мирового автомобилестроения и специфика сбыта автомобилей предопределяют сдвиги в субъектной, институциональной, товарной, географической его структуре.

Трансформация рынка автомобилей характеризуется его распределением между ведущими традиционными производителями и относительно молодыми участниками, преимущественно из азиатских стран.

На начало 2013 г. 6 крупнейших ТНК в области автомобилестроения обеспечивали свыше 54 \% совокупного мирового спроса. Речь идет о таких компаниях, как Toyota Motor Corporation, General Motors, Volkswagen AG, Hyundai Motor Company, Ford Motor Company, Alliance Renault-Nissan. Весьма высок уровень специализации производителей агрегатов, узлов, деталей и т.д. Существует несколько крупнейших корпораций в смежных отраслях, специализирующихся на выпуске определенных деталей и комплектующих для производства конечной продукции.

Таким образом, мировой рынок автомобилей становится все более монополизированным, и главные позиции на нем занимают ведущие ТНК. Можно утверждать, что «лицо» мирового рынка сформировалось, и в обозримой перспективе можно будет говорить только о возможных перемещениях компанийлидеров по отношению друг к другу.

Глобальную конкуренцию от традиционной отличают: одновременность развития сразу во всех проявлениях; многомерность обострения на разных уровнях; нарастание динамизма изменений; активность конкурентов; изменение форм во всех сферах конкуренции - эффективности, качества, гибкости, цикла, новаторства и развития НИОКР, условий труда

\begin{tabular}{|c|c|c|}
\hline \multicolumn{3}{|c|}{ Динамика продаж автомобилей в мире } \\
\hline \multicolumn{3}{|c|}{ в 2005-2013 гг. } \\
[The dynamics of car sales in the world in 2005-2013] \\
\hline Период, & Среднегодовые темпы & Объем продаж \\
г. & прироста объема продаж, & легковых автомобилей \\
\hline 2006 & с 2011 г. - ежегодные, \% & в 2013 г., шт. \\
\hline 2007 & 5,6 & \\
\hline 2008 & 5,9 & \\
\hline 2009 & $-1,8$ & \\
\hline 2010 & $-0,6$ & \\
\hline 2011 & 12,3 & \\
\hline 2012 & 3,4 \\
2013 & 5,4 \\
\hline
\end{tabular}

Примечание. Составлено автором по материалам [2].

и отношения к людям, структуре производственных процессов. Именно степень соответствия, а тем более опережения конкурентов определяют лидеров и проигравших на мировом рынке легковых автомобилей.

Одним из важных факторов в развитии мирового авторынка становится ослабление позиций в экспорте развитых «традиционных» стран и усиление позиций новых индустриальных стран.

Вычисленные темпы прироста экспорта по направлениям потоков свидетельствуют, что особенно быстро растут внутренние азиатские поставки автомобилей, а также поставки автомобилей из Азии в Европу. Так, сегмент «Север-Юг» занимает 7,9 \% мирового экспорта автомобилей. Однако внутренняя европейская торговля остается все еще на первом месте, занимая 55,6 \% от общего объема.

Основные факторы, влияющие на такое распределение экспорта - это рост экономики и общий рост платежеспособности населения во многих развивающихся странах, при том что в развитых странах уже давно отмечается перепроизводство автомобилей.

Общее количество стран-импортеров почти в 1,5 раза превосходит количество стран-экспортеров мира. Как следует из статистических данных ВТО, мировой экспорт, а также импорт автомобилей имеют тенденцию к росту. Но импорт растет медленнее, поскольку ограниченность региональных рынков, обусловленная спецификой потребления и, в значительной мере, особенностями местного менталитета, налагает свой отпечаток на формирование конечного спроса на региональных и мировом рынках.

Основными потребителями иностранных автомобилей за последние два десятилетия были Западная Европа - 25 \% общей стоимости импорта и Северная Америка - 12,9 \% [3]. Прирост импорта в этих регионах составил $61 \%$ и $15 \%$ соответственно. Основной вклад в развитие европейского импорта вносят Германия, Франция и Испания. Однако наиболее быстрорастущими рынками импортных автомобилей были Китай и Россия (до 2009 г.).

Номенклатура продукции автомобильной промышленности, которая продается на различных рынках, весьма различается в зависимости от региональ- 


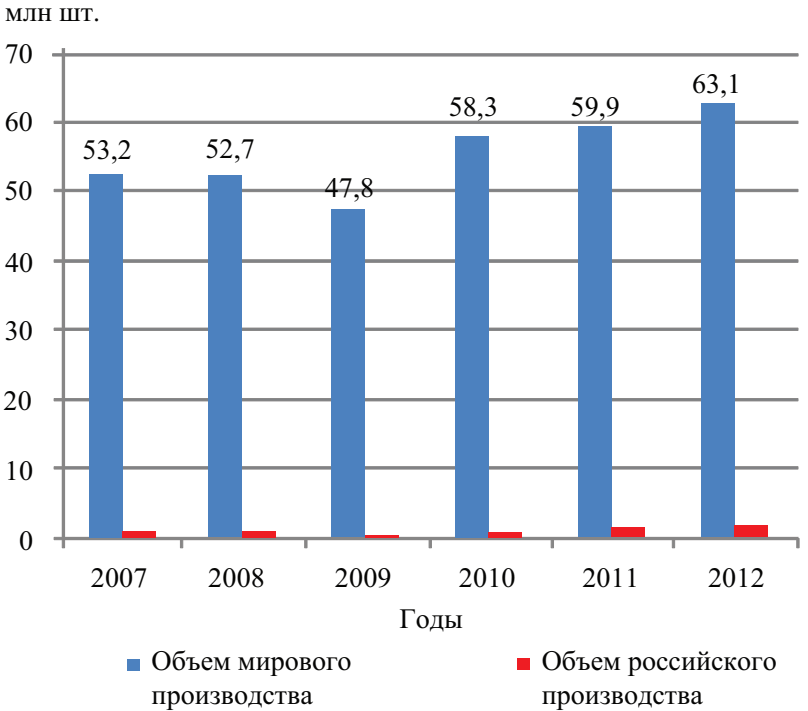

Рис. 1. Динамика мирового производства легковых автомобилей в 2007-2012 гг.

[Dynamics of world production of passenger cars in 2007-2012]

Примечание: составлено автором по данным [2].

ных и страновых особенностей структуры спроса, которая формируется в зависимости от предпочтений потребителей по классу и стоимости автомобилей, также уровня собственной платежеспособности.

Европейские потребители предпочитают менее мощные машины, но со значительно более качественной отделкой салона, а также с продуманными конструкцией и техническим оснащением.

В Азиатско-Тихоокеанском регионе (АТР) основным фактором спроса является уровень дохода населения. В силу того, что он сравнительно невысок, здесь наибольшим спросом пользуются более дешевые автомобили.

Ужесточение конкуренции, резкое падение спроса в развитых странах в 2008-2009 гг., а также большой потенциал рынков развивающихся стран и возможность получения льготных условий создают все больше стимулов для вывода производства в эти страны. Например, доля затрат на труд в цене (или себестоимости) автомобиля в Китае составляет только 5 \%, в России - $6 \%$. В США этот показатель равен 14 \%, в Японии - $19 \%$, а в странах Европы - в среднем $13 \%$ [4].

Помимо собственно производства ведущие производители начинают вывод в развивающиеся страны также и своих исследовательских и опытно-конструкторских мощностей. Основными участниками этого процесса стали Китай, Мексика, Индия. Однако Россия не уделяет должного внимания этой тенденции.

В целом же в мире в 2013 г. было реализовано более 62 млн единиц легковых автомобилей, что на 4 \% больше, чем в предыдущем году (рис. 1).

На данный момент мировой рынок автомобилей отличает неоднородность, и развитие его проходит непропорционально. На крупнейших авторынках мира в 2012 г. демонстрировались различные тенденции. Например, на рынке США спрос приблизился к Своему уровню до начала кризиса 2008 г., Китай сумел сохранить положение крупнейшего авторынка мира, в Европе продажи машин резко снизились на фоне финансового кризиса, а на российском автомобильном рынке продолжился рост.

Крупнейшая доля проданных в мире автомобилей приходится на Китай. Как следует из данных Ассоциации автопроизводителей Китая (CAAM), в 2013 г. в Китае было продано на 15 \% машин больше, чем в 2012 г. Число проданных в 2013 г. новых легковых машин составило более 17 млн штук [5].

Существенный рост на автомобильном рынке Китая начался в 2009 г., когда увеличение спроса на китайские машины достигло 59,1 \% по сравнению с этим же показателем предыдущего года. На китайском авторынке продолжается стабильный подъем, несмотря на значительное замедление темпов роста.

Лидерами роста на автомобильном рынке Китая в 2012 г. (без учета собственно китайских марок) были преимущественно европейские бренды высшего сегмента - BMW, Audi, Jaguar и Land Rover. Спрос на марки автомобилей $B M W$ (326 тыс. шт.) и Audi (405,8 тыс. шт.) вырос на 30-40 \%, а для автомобилей таких марок как Jaguar и Land Rover, Китай стал важнейшим рынком сбыта. Спрос на эти марки вырос на 70 \% (73,3 тыс. шт. в сумме для обоих брендов).

В январе/феврале 2013 г. продажи легковых машин в Китае выросли наибольшими темпами с 2010 г., несмотря на ухудшение макроэкономических показателей КНР. В 2011 г. наблюдался рост на 2,5 \%, в 2012 г. - на 4,3 \%. Как говорят данные CAAM, продажи машин дилерам за первые два месяца 2013 г. выросли на $20 \%$ - до 2,84 млн машин. При этом CAAM прогнозирует, что дальнейшему росту рынка автомобилей КНР будут содействовать восстановление экономического роста и продолжающаяся урбанизация.

Положительные тенденции роста наметились и на американском автомобильном рынке. Объем продаж в США в 2013 г. достиг 7,6 млн легковых машин. Годовой прирост составил $4 \%$.

По мнению автора, расширению авторынка США поспособствовал экономический рост в стране, а также рост уверенности американских потребителей в завтрашнем дне. Многие автовладельцы, придержавшие свои старые машины во времена рецессии, решили обновить свой автопарк. У многих людей появилось больше уверенности в перспективах трудоустройства, а банки стали более открытыми. Эти факторы повлияли на возвращение покупателей на рынок [6].

Лидерами роста продаж в США в 2012 г. стали такие марки, как Volkswagen благодаря своей модели Passat. При этом удалось превысить заданный план продаж в 500 тыс. машин. За ноябрь 2012 г. компания смогла продать в США 577 тыс. автомобилей [7]. Также в числе лидеров был Chrysler со своими автомобилями Dodge Caravan и Jeep Grand Cherokee.

По итогам февраля 2013 г. на американском авторынке темпы роста составили $4 \%$, то есть более чем 
1,2 млн легковых автомобилей. Наибольший рост продаж за первые два месяца 2013 г. продемонстрировали такие компании, как Volkswagen, Ford и General Motors.

Объем реализации на рынке Японии в 2012 г. вырос на 26 \% и достиг показателя в 3,39 млн проданных единиц. При этом было приобретено 1,98 млн миникаров - микролитражных автомобилей с объемом двигателя до $660 \mathrm{~cm}^{3}$. Эти автомобили набирают популярность в последнее время как наиболее экономичный вид легкового транспорта [8]. Причиной такого роста стали государственные субсидии, направленные на популяризацию экологичных автомобилей.

Господдержка способствовала стабилизации на автомобильном рынке Японии и началу нового роста рынка после спада в марте 2011 г. из-за мощного землетрясения, которое нанесло большой урон японским автопроизводителям, а также дилерам и потребителям, что парализовало рынок автомобилей на целый год. Сегодня госпрограмма субсидирования приобретения экологически чистых автомобилей прекращена, но за время ее реализации этим успело воспользоваться большое количество японских потребителей, что прямо отразилось на развитии рынка автомобилей. Тем не менее, несмотря на общий прирост, за последние месяцы 2012 г. продажи автомобилей в Японии сократились. Наиболее существенное падение составило 9 \% в октябре. Согласно данным Японской ассоциации автодилеров (JADA) [9], объемы продаж автомобилей в феврале 2013 г. сократились на 13,3 \% до 261585 единиц. В результате завершения госпрограммы по субсидированию экологически чистых автомобилей, а также в связи возможным ростом налогов и ростом цены страхования в JADA прогнозировали падение продаж на японском автомобильном рынке в 2013 г. на 13 \% к показателю предыдущего года (3,014млн).

Социально-экономическая обстановка в европейских странах не могла не оказать влияния на состояние европейского авторынка. В настоящее время автомобильный рынок Европы пребывает в состоянии кризиса. В некоторых европейских странах в 2012 г. объем продаж автомобилей снизился до минимальных количеств. В декабре 2012 г. в ЕС имел место самый мощный спад продаж новых машин с 2008 г., а именно на $16,3 \%$. Таким образом, годовой показатель упал на 8,2 \%, составив 12 млн единиц. Это наихудший результат продаж с 1995 г. На основных рынках ЕC, кроме британского, в декабре 2012 г. также имел место спад: в Германии - на $16 \%$, во Франции - на $15 \%$, в Италии на $22,5 \%$, в Испании - на $23 \%$.

Причинами спада объемов продаж на европейских автомобильных рынках могли быть долговой кризис и общая политическая и экономическая нестабильность в зоне валюты евро в сочетании с различными неблагоприятными для бизнеса налоговыми инициативами, а также с новыми ужесточениями в области выбросов в атмосферу, которые принимаются сегодня в ЕС.

Таким образом, на данный момент ситуация на мировом рынке автомобилей нестабильна.
Одновременно с ростом продаж легковых автомобилей в Китае, Японии, США и России европейский автомобильный рынок находится в состоянии стагнации, а то и спада, что доказывают не только итоги 2012 г., но и положение в начале 2013 г.

Автомобильный рынок является весьма чувствительным к экономической ситуации в Европе, потому что автомобили являются товаром долгосрочного пользования. Люди предпочитают осуществлять такие покупки, будучи уверенными в собственных экономических перспективах.

В США возвращение покупателей на рынок в 2012 г. произошло благодаря тому, что общая стабилизация в экономике возродила у американцев уверенность в будущем.

Аналогично рост экономики Китая способствует повышению спроса на легковые машины. Вместе с тем рост объемов китайского автомобильного рынка на фоне спада в Европе влечет за собой и обострение конкуренции для китайских производителей. Конкурентная борьба на авторынке Китая будет усиливаться, поскольку иностранные компании будут наращивать меры, направленные на рост своей рыночной доли.

В 2008 и 2009 гг. как в мире, так и в России произошло ощутимое падение производства. Только в отличие от общемирового уровня объем производства на российском рынке сократился в 2009 г. почти на $60 \%$. В то время как в целом по миру падение производства составило лишь 9 \%. Докризисные объемы производства на российском рынке были восстановлены только к 2011 г., а не годом раньше, как это произошло на большинстве других рынков развитых стран. Вместе с тем в целом в течение 2007-2012 гг. основная динамика производства автомобилей в России соответствовала мировой. Доля России на мировом рынке за эти годы колебалась от 2,4 \% в 2007 г. до 3,1 \% в 2012 г. Также сильно, до 1,2 \%, она упала в 2009 г. (рис. 2).

Экономическая ситуация на автомобильном рынке в РФ сегодня отличается от общеевропейской. В 2011 г. российский авторынок перешел к росту благодаря восстановлению экономики после кризисного 2009 г., росту доходов на душу населения, восстановлению рынка автокредитования, а также реализации госпрограммы утилизации подержанных автомашин.

Однако, несмотря на оптимизм послекризисных 2009-2012 гг., в 2013 г. объем продаж на российском автомобильном рынке упал на $5 \%$ или на 2,78 млн шт. новых легковых автомобилей в физическом выражении [10]. Негативные тенденции на авторынке России стали проявляться еще в конце 2012 г. В ноябре-декабре 2012 г. рост продаж почти прекратился (рис. 3). В целом в России в 2012 г. было реализовано примерно 2597720 ед. автомобильной продукции.

Доля России на мировом автомобильном рынке в 2013 г. составила примерно 4,1\%.

Автомобильный рынок в России в 2013 г. продолжал демонстрировать негативную динамику, что к концу года выразилось в более чем 5-процентном падении продаж. 


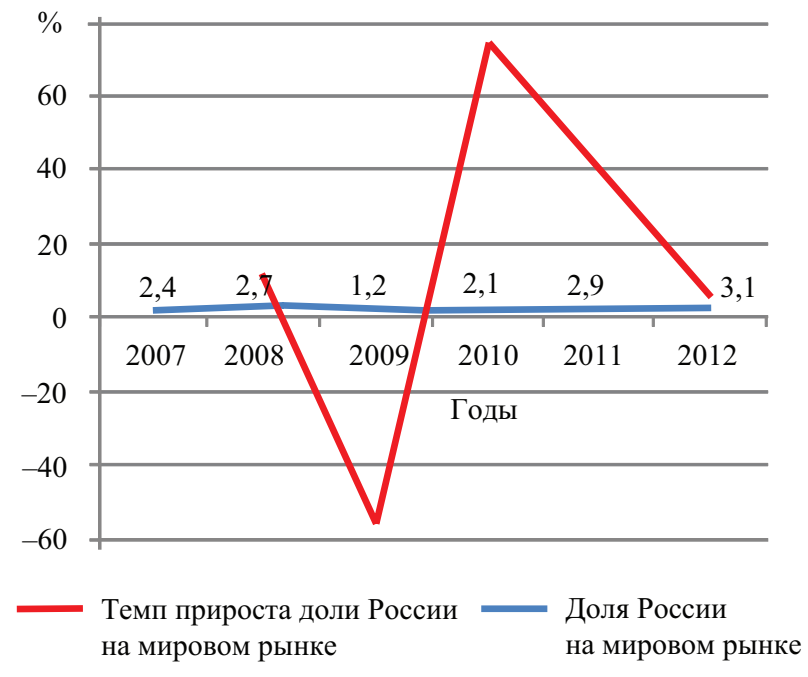

Рис. 2. Динамика доли России на мировом рынке легковых автомобилей в 2007-2012 гг.

[Dynamics of the share of Russia in the global passenger car market in 2007-2012]

Примечание: составлено автором по данным [4].

млн шт.

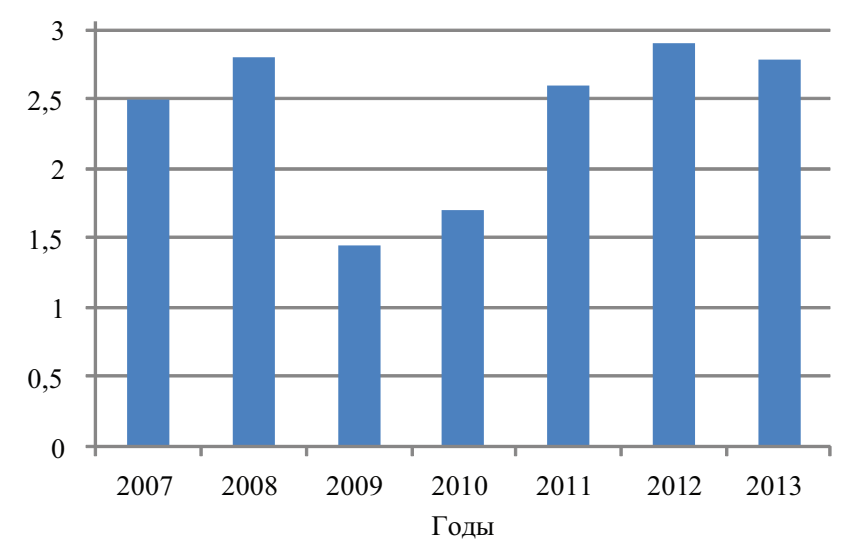

Рис. 3. Продажи новых легковых автомобилей в России в 2007-2013 гг.

[Sales of new passenger cars in Russia in 2007-2013]

Примечание: составлено автором по данным [10].

Падение продаж на рынке многие эксперты отрасли по-прежнему объясняют неуверенностью потребителей. Сама экономическая ситуация в мире и в России крайне непредсказуема. И поэтому потребители старались отложить такую ответственную покупку, как автомобиль.

Проблема сокращения спроса скорее применима к психологии потребителя, нежели основана на объективных причинах. В России не происходит действительного сокращения зарплат или падения ВВП [10, стр. 70].

Традиционно, проблемы сокращения спроса наблюдатели российского автомобильного рынка относят к таким трудностям развития, как высокая сто- имость автомобильных кредитов. Хотя при этом доля автомобилей, купленных в кредит, выросла до 50 \% по сравнению с долей в 35 \% в 2012 г. [10, стр. 71].

К негативным факторам российского авторынка в 2013 г. можно отнести рост цен на бензин, усугубление транспортных проблем в крупных городах России, а также ценовые войны производителей и дилеров.

Если говорить о распределении конкретных марок на российском авторынке в 2013 г., то лидером продаж в России все еще остается отечественная марка Lada. Однако в 2013 г. объемы продаж этой марки показали самое сильное падение на рынке, а именно на $15 \%$ (табл. 3) [10, стр. 72].

В 2013 г. продажи автомобилей всех отечественных марок снижались. Тем не менее для ОАО АвтоВАЗ 2013 г. был вполне удачным при продвижении на рынок новых моделей, таких как Lada Granta. Рост продаж этой машины составил 38 \% (до 167 тыс. шт.) [10, стр. 73]

Производители модели Renault также смогли нарастить объем продаж в 2013 г. на $11 \%$. Среди марок данной компании самым популярным в России оказался Renault Duster. Продажи данной марки выросли по итогам года на 77 \% [10, стр. 73].

Третье и четвертое места на российском рынке занимают корейские производители Kia Motors и Hyundai Motor.

Среди других успешных производителей на российском рынке можно назвать представителей брендов класса премиум, а именно Mercedes-Benz, $B M W A G$, Audi $A G$. Так, например, продажи марок Mercedes-Benz в 2013 г. возросли на $19 \%$.

Среди тенденций развития рынка наряду с уже отмеченным общим падением продаж можно назвать и трансформацию основных сегментов рынка. Главным трендом 2013 г. в России стало сокращение самого популярного сектора - автомобилей компактного класса. Еще относительно недавно на них приходилось около половины продаж на рынке России. Теперь же на них приходится только 35 \% всех проданных в России легковых автомобилей [10, стр. 73].

Место автомобилей компактного класса начинают занимать автомобили класса компактных кроссоверов. Компактные кроссоверы очень подходят именно для российского рынка. Эти машины особенно полезны при плохом состоянии российских дорог и сложных погодных условиях. И одновременно они продаются по более доступной цене, которая почти сравнялась с ценой автомобиля компакт-класса в самых дорогих комплектациях [10, стр. 73].

В качестве одного из примечательных трендов современного автомобильного рынка в России является постепенный рост средней цены машины. По данным компании «Автостат», несмотря на падение рынка в натуральном выражении, средняя цена автомобиля уже достигла 900 тыс. руб., что на 6 \% выше уровня 2012 г. [10, стр. 73].

При этом, несмотря на снижение продаж автомобилей в 2013 г., вполне возможен рост объема продаж 


\begin{tabular}{|c|c|c|c|c|c|c|}
\hline \multicolumn{7}{|c|}{$\begin{array}{c}\text { Результаты продаж новых легковых автомобилей в России в 2011-2012 гг. } \\
\text { [The results of sales of new passenger cars in Russia in 2011-2012] }\end{array}$} \\
\hline \multirow[b]{2}{*}{$\begin{array}{c}\text { Категории легковых } \\
\text { автомобилей }\end{array}$} & \multicolumn{3}{|c|}{ Продажи, тыс. шт. } & \multicolumn{3}{|c|}{ Продажи, млрд долл. США } \\
\hline & $\begin{array}{c}\text { Январь-декабрь } \\
2011 \text { г. }\end{array}$ & $\begin{array}{c}\text { Январь-декабрь } \\
2012 \text { г. }\end{array}$ & $\Delta, \%$ & $\begin{array}{c}\text { Январь-декабрь } \\
2011 \text { г. }\end{array}$ & $\begin{array}{c}\text { Январь-декабрь } \\
2012 \text { г. }\end{array}$ & $\Delta, \%$ \\
\hline Отечественные автомобили & 620 & 518 & $-6,5$ & 60,9 & 60,7 & -3 \\
\hline Иномарки российской сборки & 1040 & 1215 & +17 & 23,7 & 31,2 & +32 \\
\hline Импорт новых автомобилей & 840 & 965 & +15 & 28,3 & 33,1 & +17 \\
\hline Всего & 2500 & 2760 & +10 & 58,9 & 71 & +21 \\
\hline
\end{tabular}

Примечание. Составлено автором по данным [10].

в России в долгосрочном плане. В пользу этого вывода говорит ненасыщенность рынка. Так, на 1000 жителей России все еще приходится менее 300 автомобилей, в то время как в США этот показатель доходит до 700 машин. При этом средний возраст автомобиля в России на конец 2013 г. составлял 12 лет [10, стр. 74], что свидетельствует о необходимости обновления автопарка.

Среди тенденций развития российского авторынка будущего можно назвать обострение борьбы различных производителей за отдельные быстрорастущие сегменты рынка.

Среди проблем, создающих искусственные барьеры на пути качественного роста российского автомобильного рынка, по мнению автора, можно назвать непредсказуемость российского законодательства. В качестве примера приведем достаточно неожиданное введение высокого утилизационного сбора в размере от 17 тыс. руб.

Конечно, следует признать, что российский рынок легковых автомобилей и российское автомобилестроение заняли свои места на мировом рынке. В российские предприятия автомобилестроения и смежных отраслей приходят инвестиции. Российский рынок интересен многим производителям автомобильной техники из многих стран мира. Но нельзя с уверенностью сказать, что место, занимаемое сегодня российскими компаниями данной отрасли, можно считать удовлетворительным. Доля в общем объеме мирового производства слишком мала. Марки российских автомобилей в мире почти не известны, за исключением, пожалуй, стран СНГ.

При сохранении современных тенденций российские компании, располагающие собственными марками и товарными знаками, рано или поздно будут скуплены крупнейшими мировыми игроками и просто встроены в их глобальные производственные и сбытовые цепочки. Иными словами они перестанут быть собственно российскими. Уже к концу 2012 г. лишь 18,7 \% проданных на российском рынке автомобилей принадлежали собственно российским брендам (табл. 2). Налицо перспективы полного поглощения оставшихся российских компаний более крупными зарубежными игроками. Выросший после кризиса 2008-2009 гг. спрос на автомобили в России был удовлетворен в основном именно такими производителями как за счет импорта (35 \% рынка на конец 2012 г.), так и производствами в самой России. Российский рынок

\begin{tabular}{|c|c|c|c|}
\hline \multicolumn{4}{|c|}{$\begin{array}{l}\text { Самые популярные марки автомобилей } \\
\text { в России в } 2013 \text { г. } \\
\text { [The most popular brands of cars in Russia in 2013] }\end{array}$} \\
\hline Место & Марка & Количество продаж, шт. & $\Delta$ к 2012 г., \% \\
\hline 1 & Lada & 456309 & -15 \\
\hline 2 & Renault & 210099 & +11 \\
\hline 3 & Kia & 198018 & +6 \\
\hline 4 & Hyundai & 181153 & +4 \\
\hline 5 & Chevrolet & 174649 & -15 \\
\hline 6 & $V W$ & 156247 & -5 \\
\hline 7 & Toyota & 154812 & +1 \\
\hline 8 & Nissan & 146139 & -5 \\
\hline 9 & Ford & 106734 & -18 \\
\hline 10 & Skoda & 87456 & -12 \\
\hline 11 & ГАЗ & 82395 & -9 \\
\hline 12 & Opel & 81421 & 0 \\
\hline 13 & Mitsubishi & 78747 & +6 \\
\hline 14 & Daewoo & 60829 & -31 \\
\hline 15 & УАЗ & 51624 & -15 \\
\hline
\end{tabular}

Примечание. Составлено автором по данным [10].

и динамика продаж на нем в эти годы скорее обогащали зарубежных и аффилированных с ними российских производителей, чем собственно российские компании. Россия превратилась в страну - нетто-потребителя автомобильной продукции.

В 2012 г. было экспортировано из РФ лишь 112954 легковых автомобиля. Причем этот показатель все еще отстает от показателей, достигнутых в 2008 г. Тогда объем экспорта легковой автомобильной продукции из РФ составил 132460 машин [11]. В 2012 г. на экспорт из России ушло лишь $4 \%$ от произведенной автомобильной продукции.

В 2013 г. из России было экспортировано уже 142000 легковых автомобилей [12].

Что же может ожидать в будущем российское автомобилестроение? К настоящему времени реализовано два сценария: поглощение отечественных производителей крупными ТНК; создание современной автомобилестроительной отрасли, успешно конкурирующей на мировом уровне. По первому сценарию после перехода на рыночную модель прекратило самостоятельное существование автомобилестроение большинства стран, входивших в СЭВ. Их предприятия либо были встроены в структуру ТНК, либо были скуплены и закрыты за ненадобностью. Примером реализации второго сценария являются такие страны, как Китай и Индия, которые буквально 
на глазах вырвались в лидеры мирового, а не только внутреннего рынка. Совершенно ясно, что, обладая ресурсами, высококвалифицированными кадрами, многолетним опытом, в том числе в области высоких технологий, российские предприятия вполне в состоянии реализовать именно второй сценарий. Успех зависит не только от размера бюджетов на модернизацию, рекламу и продвижение, но в первую очередь от желания добиваться успеха и понимания, в каком направлении это делать.

\section{Библиографический список}

1. Обзор статей о компании Тойота Мотор URL:http://www.auto.vIru от 17.02.2006 (дата обращения: 05.09.2014).

2. URL:http://oica.net/category/productionstatistics/ (дата обращения: 05.09.2014).

3. Пасько А.В. Современные стратегии развития транснациональных корпораций на мировом рынке легковых автомобилей (на примере шведской компании Volvo) Автореф. дис.... канд. экон. наук: 08.00.14 / ГУУ. М., 2011. $21 \mathrm{c.}$

4. Конахина Н.А. Анализ инновационных технологий в мировой отрасли автомобилестроения // Инновации. 2008. № 2 (112). С. 60 - 61.

5. Китайский авторынок показал максимальный рост продаж // Украінска правда. Экономічна правда. 11.03.2013. // URL: http://www.epravda.com.ua/rus/ news/2013/03/11/ 364968/ (13.03.2012). (дата обращения: 05.09.2014).

6. Злобин А. Авторынок России: когда сократится отставание от США? // Forbes http:// URL: www. forbes.ru/sobytiya/rynki/83283-avtorynok-rossiikogda-sokratitsyaotstavanie-ot-ssha (дата обращения: 31.03.2013).

7. United States Car Registrations // URL: http:// www.tradingeconomics.com/unitedstates/carregistrations (дата обращения: 31.03.2013).

8. Новая тенденция мирового автомобильного рынка: Хонда переходит на эко-двигатели // Autoroute. ru // URL: http://avtoroute.ru/novaya-tendenciyamirovogoavtomobilnogorynka-xonda-perexodit-na-ekodvigateli.html (дата обращения: 31.03.2013).

9. Японский авторынок падает шесть месяцев подряд // Аналитическое агентство «Автостат» // URL: http://www.autostat.ru/news/view/12852/ (дата обращения: 26.03.2013).

10. Грамматчиков Алексей. «На дне». Эксперт. № 5. 27 января - 2 февраля 2014.

11. URL: http://gloriaputina.livejournal.com/284260. $\mathrm{html}$ Реальность против мифологем. Экспорт, импорт автомобилей в СССР и РФ: сборная статистика 2001 2012 гг. (дата обращения: 26.03.2013).

12. URL: http://www.zr.ru/content/news/614771eksport-avtomobilej-iz-rossii-vyrastet-v-7-raz/ Экспорт автомобилей из России вырастет в 7 раз. (дата обращения: 26.03.2013).
Ekonomika $v$ promyshlennosti=Economy in the industry 2014, no. 4(24) - October - December, pp. 124-131 ISSN 2072-1633

The Russian passenger car market, as part of the global market. The state and prospects of development

I. Ya. Gal'perin - Moscow State Institute of International Relations (University) MFA of Russia, 6, Prospect Vernadskogo, Moscow, Russia, 119454, galperin_igor@mail.ru.

Abstract. Over the past 20 years, the automotive products market in Russia has significantly changed. In the early 90's our market was mostly dominated by local manufacturers. Despite substantial claims of customers concerning the quality of cars, the industry looked to be advantageous due to the relatively low prices for their products and developed network of car dealers and car repair garages, where it was possible at any moment to repair the car or buy spare parts. Foreign manufacturers could offer the consumer a good quality, but at a higher price. However, the image of the Russian car market in the 90's began to change. Burdened by the problems of the transition economy, the Russian manufacturers could not and did not want to invest in the modernization of production and a in acute long term quality increase. Moreover, they did not have the proper incentives. The customs protection in internal Russian car market created an artificial price protection for domestic manufacturers. On the one hand, the customs protection prevented the bankruptcy of domestic manufacturers and related industries, saved millions of jobs and stable taxpayers. But on the other hand, the situation contributed to the preservation of many negative and non-market factors of automobile companies, lacking again the stimulus for large-scale upgrade and transition to new approaches. Russia's entry to the World Trade Organization means that Russian producers will be forced to exist on the domestic market on equal terms with major international competitors.

Keywords: automotive market, automotive, automobile, motorcar, automobile industry, development of the automotive industry, the domestic auto industry.

\section{References}

1. Obzor statei o kompanii Toiota Motor [Overview of articles about company Toyota Motor] Available at: http://www.auto.vlru ot 17.02.2006 (accessed: 05.09.2014). (In Russ).

2. Available at: http://oica.net/category/productionstatistics/ (accessed: 05.09.2014). (In English). 
3. Pas'ko A.V. Sovremennye strategii razvitiya transnatsional'nykh korporatsii na mirovom rynke legkovykh avtomobilei (na primere shvedskoi kompanii Volvo) [Modern development strategies of transnational corporations in the global passenger car market (for example, the Swedish company Volvo)] Avtoref. dis.... kand. ekon. nauk: 08.00.14 / GUU. M., 2011. 21 s. (In Russ).

4. Konakhina N.A. Analysis of innovative technologies in the global automotive industry // Innovatsii. 2008. no. 2 (112). S. 60 - 61. (In Russ).

5. The Chinese car market showed the maximum increase sales // Ukrainska pravda. Ekonomichna pravda. 11.03.2013 // Available at: http://www.epravda.com. ua/rus/news/2013/03/11/ 364968/ (13.03.2012). (accessed: 05.09.2014). (In Ukrainian).

6. Zlobin A. The Russian automotive market: when will decrease the gap with the US? // Forbes http:// Available at: www.forbes.ru/sobytiya/rynki/83283avtorynok-rossii-kogda-sokratitsyaotstavanie-ot-ssha (accessed: 31.03.2013). (In Russ).

7. United States Car Registrations // Available at: http://www.tradingeconomics.com/unitedstates/carregistrations (accessed: 31.03.2013). (In English).
8. The new trend of the world automotive market: Honda goes on eco-engines // Autoroute.ru // Available at: http://avtoroute.ru/novaya-tendenciyamirovogoavtomobilnogorynka-xonda-perexoditna-eko-dvigateli.html (accessed: 31.03.2013). (In Russ).

9. The Japanese market falls six months in a row // Analiticheskoe agentstvo «Avtostat» // Available at: http:// www.autostat.ru/news/view/12852/ (accessed: 26.03.2013). (In Russ).

10. Grammatchikov Aleksey. «Na dne», [On the bottom] Ekspert, no.5. 27 yanvarya - 2 fevralya 2014. (In Russ).

11. Available at: http://gloriaputina.livejournal. com/284260.html Real'nost' protiv mifologem. Eksport, import avtomobilei v SSSR i RF: sbornaya statistika 2001-2012 gg. (accessed: 26.03.2013). (In Russ).

12. Available at: http://www.zr.ru/content/ news/614771-eksport-avtomobilej-iz-rossii-vyrastet-v7-raz/ [Exporting cars from Russia will grow by 7 times] (accessed: 26.03.2013). (In Russ).

Information about authors: Applicant for the degree of candidate of economic Sciences.

\section{Текущие проблемы развития мировой алмазной промышленности}

(C) 2014 г. С.Ю. Черников

Современная алмазная промышленность является важным звеном мировой экономики. Отрасли извлечения и вывоза алмазного сырья обеспечивают значительную часть ВВП в экономиках многих развивающихся стран. Развитые страны, такие как Бельгия, Нидерланды, Израиль, Великобритания, получают высокие доходы от операций по обработке, сортировке, огранке поступающих алмазов и, естественно, дальнейшей дистрибуции изделий с бриллиантами. Данный сектор промышленности представляет большой экономический и социальный интерес и для России, которая на сегодняшний день является крупнейшим поставщиком алмазов на мировой рынок (в физических объемах). Подавляющая часть натуральных алмазов используется в ювелирной промышленности, причем общий объем конечного рынка изделий с бриллиантами оценивается более чем в 70 млрд долл. Однако современная алмазная индустрия сталкивается с рядом проблем структурного характера, которые могут кардинально изменить облик данного сектора в течение следующих 5 лет.

Ключевые слова: алмазы, бриллианты, проблемы рынка алмазов, мировые рынки, добыча алмазного сырья.

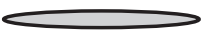

* Канд. экон. наук, доц. каф. маркетинга экономического факультета Российского университета дружбы народов (РУДН). 117198, Москва, ул. Миклухо-Маклая, д. 6, Россия, chernikov.mirbis@gmail.com.
Исторически первые месторождения алмазов были открыты в Индии более 15 веков назад. Естественно, ни о каких существенных объемах добычи речи не шло. Камни в основном оседали в сокровищницах индийской знати и вплоть до XXIII вв. не являлись предметом международной торговли. Однако после завоевания части индийских территорий персами и путешествия Марко Поло 